\title{
KEPEMIMPINAN TRANSFORMASIONAL PROFETIK DALAM MENGEMBANGKAN PESANTREN DI KABUPATEN JEMBER
}

\author{
Umiarso \\ Universitas Muhammadiyah Malang \\ Jl. Bandung 1 Malang, Jawa Timur, 65144 \\ Email:umiarso@umm.ac.id
}

\begin{tabular}{c|c|c}
\hline Received: & Revised: & Approved: \\
25/07/2018 & $\mathbf{0 7 / 0 8 / 2 0 1 8}$ & $\mathbf{1 8 / 0 8 / 2 0 1 8}$ \\
\hline
\end{tabular}

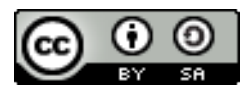

Kepemimpinan Transformasional Profetik Dalam Mengembangkan Pesantren Di Kabupaten Jember licensed under a Creative Commons Attribution-Share A like 4.0 International License

\begin{abstract}
Pesantren (Islamic boarding schools) has been continuously aligning its educational system with the needs of society and the times. The development of pesantren is inseparable from the role of kiai in carrying out the institutional transformation. This study focuses on transformational leadership of the kiai in developing the pesantren institution. The results of this study indicate that the concept of developing pesantren is transcultural with the principle of "accepting a new good culture and preserving the old one that is still relevant", based on the vision and mission, directed at an integrative education system which combines the mind and heart traditions using rational domain and spirituality in order to achieve worldly (profanistic) and ukhrawi (sacralistic) goals; transformational leadership styles of a kiai include idealized influence behavior, inspirational inspiration, intellectual stimulation, individual consideration, and individual spiritual greatness; and the implications of transformational leadership include two dimensions, namely the human resources and institutional resources. Therefore, this leadership can be
\end{abstract}


said to be prophetic transformational leadership with the addition of individual spiritual greatness (Five I'S).

Keywords: Kiai, Transformational Leadership, and Pesantren.

\begin{abstract}
Abstrak
Pesantren secara kontinu menyelaraskan sistem kependidikannya dengan kebutuhan masyarakat serta perkembangan zaman. Pengembangan pesantren tidak terlepas dari peran kiai dalam melakukan transformasi kelembagaan. Penelitian ini memfokuskan pada kepemimpinan transformasional kiai dalam mengembangkan kelembagaan pesantren. Hasil penelitian ini menunjukkan bahwa konsep pengembangan pesantren bersifat transkultural dengan prinsip "menerima budaya baru yang baik dan melestarikan budaya lama yang masih relevan", berpijak pada visi dan misi, diarahkan pada sistem pendidikan integratif yang memadukan antara tradisi akal dan hati menggunakan domain rasional dan spiritualitas untuk mencapai tujuan yang bersifat duniawi (profanistik) dan ukhrawi (sakralistik); gaya kepemimpinan transformasional kiai meliputi perilaku idealized influence, inspirational inspiration, intellectual stimulation, individual consideration, dan individual spiritual greatness; dan implikasi kepemimpinan transformasional meliputi dua dimensi, yaitu dimensi sumberdaya manusia dan kelembagaan. Karenanya, kepemimpinan ini dapat dikatakan kepemimpinan transformasional profetik dengan penambahan individual spiritual greatness (Five I'S).
\end{abstract}

Kata Kunci: Kiai, Kepemimpinan Transformasional, dan Pesantren

\title{
A. Pendahuluan
}

Pesantren al-Falah Karangharjo -selanjutnya ditulis PFK- dan pesantren Nurul Islam Antirogo -selanjutnya ditulis PNIA- tidak lepas dari "sistem kerajaan". Dua pesantren ini memiliki corak sintesis dengan latar perkembangan yang berbeda, PFK berkembang dari tradisional-salaf ke modern, sedangkan PNIA sendiri sejak berdirinya telah bergerak di arus modern. Namun, ia tetap memasukkan kitab kuning yang dihasilkan para ulama' di masa lalu khususnya yang berasal dari Timur Tengah sebagai lokus keilmuan mereka.

Pada saat ini, kiai PFK (KH. Abdul Muqit Ariev -selanjutnya ditulis AMA-) dan PNIA (KH. Muhyiddin Abdusshomad -selanjutnya 
ditulis MA-) membenahi dan mengembangkan lembaga pesantren. Namun ia terkesan memiliki karakteristik sama dengan pesantren lain, cenderung elitis dan jauh dari realitas sosial yang penuh permasalahan sosial (kemiskinan, dehumanisasi dan dekadensi moral) dan terlalu berorientasi teosentris. Kondisi ini diperparah dengan masalah keilmuan pesantren yang mengalami kesenjangan, keterasingan dan diferensiasi antara keilmuan agama dengan dunia modern.

Dengan demikian, kedua pesantren ini mempunyai tugas ganda untuk diwujudkan, yaitu: pertama, mewujudkan manusia dan masyarakat muslim beriman dan bertaqwa kepada Allah. Sehingga pesantren tidak hanya berfungsi sebagai "lembaga ketuhanan" yang berorientasi ke "kepentingan langit", tetapi ia melakukan reproduksi ulama' yang memiliki kualitas keIslaman, keilmuan, dan akhlaq. Kedua, mencetak lulusan pesantren sebagai ilmuwan sesuai kebutuhan zaman dan perkembangan ilmu pengetahuan dan teknologi. Menariknya, kiai kedua pesantren tersebut merespon tuntutan ini dengan tidak mencabut akar tradisi, mereka konsisten dengan nilai-nilai spiritualitas keislaman. Bagi mereka, pesantren sebagai lembaga pendidikan perlu untuk ikut berperan serta dalam pergumulan pengembangan ilmu pengetahuan dan teknologi yang dilandasi spirit integrasi dengan nilai-nilai spiritualitas Islam.

Awal-awal diterapkannya tugas tersebut berimplikasi pada pemisahan tradisi lama dengan unsur-unsur baru. Namun, gerak dinamis manajerial kelembagaan pesantren yang terus menerus merespon perubahan -baca unsur-unsur baru- mampu terintegrasi dengan tradisi lama. Di sisi yang lain, ia mampu mengurai problematika pesantren yang bersifat kekinian melalui pendekatan kontemporer seperti tata manajerial pendidikan pada sistem pembelajaran yang tidak terstandar digerakan ke arah standarisasi mutu pendidikan; atau pola kelembagaan pesantren yang salaf murni digerakan menuju ke khalaf.

Spirit yang berada dibalik kerangka proses transformatif tersebut adalah spirit modernisasi pemikiran terutama kelembagaan pesantren. Modernisasi ini oleh AMA maupun MA dinilai urgen untuk diimplementasikan dilembaganya sebagai bentuk kedinamisasian dunia mereka maupun diri mereka sendiri. Karenanya, dua kiai ini 
secara kontinu menyelaraskan sistem kependidikan pesantren mereka dengan pola kebutuhan masyarakat serta arus perkembangan ilmu pengetahuan dan teknologi.

Lazim apabila kedudukan kiai di pesantren begitu sentral, di samping sebagai pendidik dan pengajar, kiai juga merupakan pemegang manajerial pesantren. ${ }^{1}$ Oleh sebab itu, tingginya status dan besarnya peran kiai dalam pembinaan dan pengembangan lembaga pendidikan pesantren menjadikannya sebagai sosok yang sangat berpengaruh dan disegani di komunitas pesantren, bahkan terhadap masyarakat di luar pesantren. ${ }^{2}$ Lazim jika kiai melalui pesantren memiliki pengaruh yang luar biasa; bahkan pesantren sendiri pun diklaim sebagai entitas yang memiliki peluang besar menjadi pusat peradaban umat Islam; ${ }^{3}$ termasuk juga dalam hal ketahanan pangan. ${ }^{4}$

Di PFK pun segala kebijakan (keputusan) kependidikan pesantren berada di AMA sebagai pemegang palu kebijakan. Prakteknya pesantren ini menerapkan asas demokrasi melalui forum syuro (musyawarah), namun tetap mempertimbangkan kebijakan diri kiai sebagai barometer keputusan mereka. Di PNIA sendiri yang tampak adalah kebijakan MA yang diterjemahkan dalam bentuk program pesantren, sehingga kebijakannya sangat mewarnai citra pesantren yang notabene memunculkan polaritas program pesantren modern. Semua kebijakan yang dicetuskan oleh kedua kiai tersebut diikuti dan diterapkan dengan berlandaskan pada "konsep barakah" yaitu suatu keyakinan akan mendapatkan reward dari Tuhan atas diri mereka yang telah melakukan atau menjalankan amanah kiai. Tata nilai ini ditekankan pada fungsi mengutamakan nilai ibadah dalam

${ }^{1}$ Ngainun Na'im, “Pesantren dan Pembentukan Manusia Karakter," Al-Afkar: Journal for Islamic Studies 1, no. 2 (Maret 2013): 10; Ali Anwar, Pembaruan Pendidikan di Pesantren Lirboyo Kediri (Yogyakarta: Pustaka Pelajar, 2011), 226.

2 Ira M. Lapidus, Sejarah Sosial Ummat Islam: Bagian Kesatu \& Dua Peterj.: Ghufron A. Mas'adi (Jakarta: Rajawali Pers, 2000), 740; Taufiq Ismail, dkk, Membangun Kemandirian Umat di Pedesaan: Ikhtiar dan Peran Pesantren Pertanian Darul Fallah 19602000 (Bogor: Pesantren Pertanian Darul Fallah, 2000), 50.

${ }_{3}$ Imam Mustofa, "Menjadikan Pesantren Sebagai Pusat Peradaban Muslim di Indonesia," Millah: Jurnal Studi Agama 11, no. 1 (2011): 75-108, https://doi. org/10.20885/millah.vol11.iss1.art4.

${ }^{4}$ Septalina Pradini dkk., "Pesantren Transformation System in The Food Sustainability," International Journal of Development and Economic Sustainability 4, no. 2 (April 2016): 1-18. 
rangka pengabdian dan pemuliaan terhadap kiai sebagai jalan untuk memperoleh pengetahuan agama yang hakiki.

Oleh sebab itu, bangunan tradisi kehidupan pesantren memiliki budaya, norma, dan sistem nilai sendiri yang berbeda dengan masyarakat sekitarnya. Kedua pesantren tersebut membangun tradisi kehidupannya berdasarkan pada ideologi serta pandangan al-salaf alshalih yang terkodifikasi dalam kitab kuning yang dijadikan referensi normatif di pesantren tersebut. Dhofier memandang pola ini suatu kelaziman, di mana tata perilaku di setiap lingkungan pesantren terbentuk dari makna hasil intepretasi teks-teks keagamaan (alQur'an dan al-Hadist) serta kitab klasik (kitab kuning). ${ }^{5}$ Pada konteks tata kehidupan inilah Wahid mengistilahkan pesantren sebagai suatu sub-kultur; ${ }^{6}$ dan Azra sebagai sub kultur setelah masyarakat. ${ }^{7}$

\section{B. Fokus Penelitian}

Penelitian ini difokuskan pada gaya kepemimpinan transformasional kiai dengan mengangkat pertanyaan bagaimana konsep pengembangan pesantren, gaya dan implikasi kepemimpinan transformasional kiai dalam mengembangkan PFK dan PNIA Kabupaten Jember?.

\section{Gaya Kepemimpinan Transfomasional Kiai dalam Pengembangan PFK dan PNIA}

Gaya kepemimpinan transformasional diterapkan oleh kiai dalam rangka mengembangkan pesantren tanpa memunculkan geliat destruktif. Perilaku kepemimpinannya bisa berbentuk sifatsifat keteladanan (role mode) yang ditunjukkan dan dikagumi civitas pesantren. Hal ini menunjukkan, kepemimpinan kharismatik yang lazim muncul di pesantren tidak cukup menjadi medium pengembangan pesantren. Apalagi kharisma tidak cukup dalam

${ }^{5}$ Zamakhsyari Dhofier, Tradisi Pesantren: Studi Tentang Pandangan Hidup Kiai (Jakarta: LP3ES, 1994), 55.

${ }^{6}$ Abdurrahman Wahid, Menggerakkan Tradisi (Yogyakarta: LKiS, 2010) Bab I: Pesantren sebagai Sub Kultur.

${ }^{7}$ Azyumardi Azra, Pendidikan Islam: Tradisi dan Modernisasi Menuju Milenium Baru (Jakarta: Kalimah, 2001), 27. 
kepemimpinan transformasional; ${ }^{8}$ sebab ia mempengaruhi seluruh keadaan termasuk dari aspek emosional pengikut. ${ }^{9}$ Dalam salah satu riset di pesantren bahwa inspirasi dan motivasi yang merupakan bagian dari kepemimpinan transformasional lebih efektif daripada kiai menggunakan aspek kharismatik dalam menjalankan tata kelola kelembagaan pesantren. ${ }^{10}$

Kepemimpinan ini tidak hanya menentukan pengembangan pesantren tapi juga menggerakkan sumberdaya manusia untuk mencapai tujuan. Yukl memiliki pandangan, kepemimpinan mentransformasi menarik moral pengikut dalam upaya meningkatkan kesadaran mereka tentang moral dan menggerakkan sumberdaya dan energi mereka untuk mentransformasi institusi. ${ }^{11}$ Robbins \& Coulter pun menyatakan, kepemimpinan transformasional merangsang dan memberi inspirasi (transformasi) pengikut untuk mencapai hasil yang luar biasa. ${ }^{12}$ Pada konteks ini, penulis sepakat dengan penyataan Widayat bahwa kepemimpinan akan erlangsung efektif, jika ia berada di tangan orang-orang yang berpengalaman atau terlatih dalam memimpin. ${ }^{13}$

Selama ini, kiai di pesantren modern terutama di pesantren tradisional membangun relasi dengan civitas pesantren bersifat patroneclient (paternalistik). Dalam lingkup pembelajaran, otoritas kiai sangat mewarnai dengan berbagai nilai-nilai yang turut mengikutinya, salah satunya adalah nilai kepatuhan mutlak dan takzim terhadap kiai. Nilai ini sebenarnya merupakan nilai-nilai sufistik yang ditanamkan

8 Jay A. Conger, Charismatic Leadership, dalam Michael Armstrong, Armstrong's Handbook of Management and Leadership: a Guide to Managing for Results (London: Kogan Page, 2009), 379.

${ }_{9}$ Laban P. Ayiro, "Transformational Leadership and School Outcomes in Kenya: Does Emotional Intelligence Matter?," FIRE: Forum for International Research in Education 1, no. 1 (2014): 28.

${ }^{10}$ Nur Khusniyah Indrawati, "Management by Inspiration: Implementation of Transformational Leadership on Business at Pondok Pesantren*) Sunan Drajat," Procedia - Social and Behavioral Sciences 115, no. 21 (21 Februari 2014): 79-90, https:// doi.org/10.1016/j.sbspro.2014.02.417. 321.

${ }^{11}$ Gary Yukl, Leadership in Organizations (New Jersey: Prentice Hall, 2010),

12 Stephen P. Robbins dan Mary Coulter, Management (New Jersey: Prentice Hall, 2012), 470.

${ }_{13}$ Prabowo Adi Widayat, "Kepemimpinan Profetik: Rekonstruksi Model Kepemimpinan Berkarakter Keindonesiaan," AKADEMIKA: Jurnal Pemikiran Islam 19, no. 1 (19 Maret 2014): 27. 
pesantren terhadap santri, sehingga kiai memiliki pengaruh yang luar biasa terhadap "kepribadian santri" ${ }^{14} \mathrm{Di}$ satu sisi, melalui seperangkat materi dan metodologi yang bersifat normatif dan skolastik, peserta didik diantarkan untuk menjadi seorang yang memiliki loyalitas dan pengabdian kepada seorang kiai. ${ }^{15}$ Kiai pada posisi ini menempatkan dirinya sebagai patron yang memberikan aliran ilmu pengetahuan agama, moral, dan pembangunan masa depan (duniawi dan akhirat) yang jelas.

Kiai memiliki posisi sentral dalam kehidupan santri hingga ia dikenal sebagai pendidik, pengasuh, pengayom, dan penuntun utama. Kiai terus menerus memberikan bimbingan, pengarahan dan pendidikan kepada santri dengan pengaruh yang kuat sampai dirinya berstatus alumni. Perilaku dan sikap kiai di balut dengan nilai-nilai kharismatik mendorong dirinya menjadi contoh yang baik bagi santri dan masyarakat pedesaan terutama yang memerlukan perubahan. Akhirnya muncul gambaran kepemimpinan kiai sebagai figur sentral dalam kelembagaan pesantren dan masyarakat. Horikoshi menjelaskan, kiai mengambil peran sebagai poros hubungan antar umat dengan Tuhan dan diidealkan oleh masyarakat, serta dianggap sebagai pemimpin simbolis yang tak gampang ditiru oleh orang biasa. ${ }^{16}$

Meskipun kiai dikonotasikan sebagai kelompok tradisional, tetapi ia tidak dapat digantikan oleh tokoh non formal lainnya. Oleh karenanya, visi dan misi keilmuan kiai di pesantren beserta kualitas santri menjadi barometer penilaian masyarakat terhadap dirinya. ${ }^{17}$ Pada konteks inilah, kiai di pesantren perlu untuk menjelma sebagai sosok yang menguasai ilmu, pendorong, penge-lola, penyaring, dan transformator pesantren dari status quo ke stadium yang lebih baik.

14 Syamsul Ma'arif, "Pola Hubungan Patron-Client Kiai dan Santri di Pesantren," Ta'dib: Journal of Islamic Education (Jurnal Pendidikan Islam) 15, no. 02 (2010): 275 .

${ }^{15}$ Syamsul Ma'arif, 276.

${ }^{16}$ Hiroko Horikoshi, Kyai dan Perubahan Sosial. Peterj.: Umar Basalim E Andi Muarly Sunrawa (Jakarta: P3M, 1987), 232.

${ }_{17}$ Amir Fadhilah, "Struktur Dan Pola Kepemimpinan Kyai Dalam Pesantren Di Jawa," HUNAFA: Jurnal Studia Islamika 8, no. 1 (15 Juni 2011): 104, https://doi. org/10.24239/jsi.v8i1.89.101-120. 
Melalui gaya kepemimpinan transformasional, kiai meramu perubahan untuk mencapai kesempurnaan visi, misi dan tujuan pesantren. Apalagi pengembangan pesantren merupakan proses dari perilaku kepemimpinan kiai yang di dalamnya terdapat relasi dialektis yang bersifat kontinu. Di ranah ini pemimpin transformasional melakukan proses transformasi pengikut dengan cara memotivasi dan memodifikasi perilaku mereka serta melalui antusiasme dan optimisme yang menginspirasi. Namun, kepemimpinan kiai PFK dan PNIA dalam melakukan transformasi civitas pesantren memiliki proses yang bersifat satu arah dan mereka dibawa ke stadium yang sempurna. Lazim kepemimpinan transformasional terus menerus berupaya meningkatkan kebutuhan pengikutnya ke arah yang tinggi seperti dari kebutuhan tingkat biologis -physiological need dan safety need- ke sosio-budaya -esteem need atau self actualization- bahkan ke tingkat spiritualitas.

Namun, perilaku kepemimpinan AMA dan MA tidak hanya memenuhi kebutuhan civitas pesantren yang bersifat material, tapi kebutuhan lain seperti spiritual. Dalam proses kepemimpinan, dua kiai ini mengutamakan dan mengangungkan kemanusiaan diri civitas pesantren. Mereka sendiri berharap mendapatkan barakah atau ridha Allah dari pengabdiannya. Melihat hal ini, teori hierarki kebutuhan Maslow perlu perluasan untuk mengakomodir kebutuhan spiritual, sebagaimana diungkapkan Bass \& Riggio sendiri, hierarki kebutuhan perlu diperluas ke atas untuk melampui orientasi aktualisasi diri. ${ }^{18} \mathrm{Jadi}$, teori ini perlu direkonstruksi untuk memperluas pengklasifikasian kebutuhan manusi dengan melahirkan penambahan kelas, yaitu kebutuhan spiritual. Awalnya ia berdiri di lima klasifikasi vertikal yang berbentuk piramida, maka setelah direkonstruksi menjadi enam klasifikasi vertikal, antara lain: fisiologis, keamanan, kasih sayang dan cinta, pengakuan (harga diri), aktualisasi diri, dan spiritual.

Di satu sisi, pemimpin transformasional mengedepankan perilaku mengagungkan aspek moralitas pengikutnya, sehingga setiap langkah yang ditempuhnya tidak lepas dari nilai-nilai kemanusiaan. Sikap altruistik ini muncul dari kesadaran dirinya untuk melakukan

${ }_{18}$ Bernard M. Bass dan Ronald E. Riggio, Transformational Leadership (New Jersey: Lawrence Erlbaum Associates, Inc, 2006), 227. 
tindakan baik terhadap pengikutnya. Luthans menyatakan, kepemimpinan transformasional memang memperlihatkan nalar moralitas dan berimplikasi terhadap masalah etika. ${ }^{19}$ Dari sikap ini muncul keinginan meningkatkan potensi kemanusiaan pengikutnya dari aspek intelektual maupun moral. Begitu pula, kiai di PFK dan PNIA meningkatkan potensi civitas pesantren tidak hanya pada aspek intelektual dan moral, tapi juga spiritualitasnya. Potensi ini dikembangkan dalam manifestasi perilaku civitas pesantren sebagai abdullah dan khalifah dengan landasan kesadaran ketuhanan (Tauhid).

Artinya, perilaku kepemimpinan transformasional kiai tidak hanya berorientasi pada transformasi kemanusiaan yang bersifat profanistik, tetapi juga transendentalistik. Dari dalam diri pemimpin terdapat kekuatan yang muncul dari kesadaran ketuhanan hingga membentuk struktur paling dalam. Dari kerangka ini tercipta gagasan besar (visi dan misi), semangat (etos kerja untuk berjihad), dan dakwah yang melahirkan keteladanan, inspirasi, dan motivasi bagi pengikutnya. Kepribadian pemimpin ini tetap berpegang pada nilai-nilai normatif dilihat oleh pengikutnya sebagai simbol yang bisa ditafsirkan. Ada perilaku yang melekat kuat dalam diri mereka, yaitu: sikap humanistik-altruistik, sikap membangun perilaku konstruktif, dan sikap meningkatkan ketaqwaan serta keimanan kepada Allah.

Tiga perilaku tersebut apabila dielaborasikan dengan pemikiran Kuntowijoyo merupakan wujud dari Islam profetik dengan trilogi proses yaitu humanisasi, liberasi, dan transendensi; yang dihasilkan dari intepretasi QS. Ali Imran: 110; Hamid \& Juliansyahzen menyatakan prinsip ini merupakan prinsip dasar kepemimpinan profetik..$^{20}$ Dengan demikian, perilaku kiai mendengungkan proses transformasi (hijrah) yang tidak hanya bermakna manifes yaitu perubahan aspek pertumbuhan kelembagaan pesantren dari titik trandisionalis (salaf) menuju ke modernis (khalaf), tapi juga bermakna laten yaitu perubahan dari kualitas kemanusiaan yang destruktif

${ }^{19}$ Fred Luthans., Organizational Behavior: An Evidance-Based Approach (New York: McGraw-Hill, 2011), 431.

${ }^{20}$ Noor Hamid dan Muhammad Iqbal Juliansyahzen, "Prophetic Leadership in Pesantren Education: Study at Pondok Pesantren Universitas Islam Indonesia," Jurnal Pendidikan Islam 6, no. 2 (27 Desember 2017): 349, https://doi.org/10.14421/ jpi.2017.62.349-369. 
menuju konstruktif (insan kamil). Effendi menyatakan, hijrah secara metafora merupakan usaha mengadakan perubahan dari suatu kondisi yang jelek menuju kondisi yang lebih baik secara terus menerus sehingga terwujud kondisi umat terbaik (khayra ummah) yang dalam perspektif al-Qur'an memiliki trilogi prinsip: Al-amru bilma'ruf (humanisasi), An-nahyu 'anil-munkar (liberasi), dan Al-imanu billah (transendensi) (QS. Ali `Imran: 110). ${ }^{21}$

Berdasarkan hal tersebut, "transformasi' merupakan pola perubahan yang mengintegrasikan orientasi keduniawian dan keakhiratan. Dengan pola ini, kiai menuntun pengikut meraih kemenangan yang bersifat nisbi sekaligus yang hakiki; antara yang profan dan transendental. Karenanya, kiai ketika menggerakkan pengikutnya menggunakan pikiran dan intuisi berlandasakan pada humanisasi-altruistik dan ketauhidan hingga dalam diri pemimpin dan pengikut muncul kesadaran ketuhanan.

Kesadaran ketuhanan sendiri dalam al-Qur'an dinyatakan sebagai tujuan diutusnya Nabi dan Rasul, yaitu untuk mencapai kesadaran ketuhanan yang maha hadir -yang sering disebut oleh Nurcholish Madjid dengan kesadaran ketuhanan yang omnipresentsekaligus kesediaan menyesuaikan diri di bawah cahaya kesadaran ketuhanan tersebut. ${ }^{22}$ Jelasnya, kepemimpinan ini menampilkan pengaruhnya pada tiga ruang yang saling terkait, yaitu: penyadaran hati, pencerahan jiwa, dan realisasi visi. Pastinya, seperti yang diungkap Spears, pemimpin ini memiliki pandangan jauh ke depan mengenai waktu dan peristiwa; serta dapat mereproduksi visi, dari generasi ke generasi, melalui kata-kata, pemodelan, citra, dan asosiasi. $^{23}$

Lazim apabila pemimpin transformasional kiai mendorong semua unsur yang ada dalam struktur lembaga pendidikan agar dapat bekerja atas dasar sistem nilai luhur. Dengan memperhatikan sisi humanistik pengikut, ia mengayomi mereka di atas prinsip

${ }^{21}$ Djohan Effendi, Pesan-Pesan al-Qur'an: Mencoba Mengerti Intisari Kitab Suci (Jakarta: Serambi, 2012), 491.

${ }^{22}$ Budhy Munawar Rachman, Kontekstualisasi Doktrin Islam dalam Sejarah (Jakarta: Paramadina, 1995), xv.

${ }^{23}$ Ulf Spears, Coaching Leadership Families: Using the Leadership Family Model to Coach, Mentor and Multiply Healthy Families (Oregon: Xlibris Corporation, 2012), 9. 
ketauhidan yang direpresentasikan lewat perilaku-perilaku konstruktif seperti amar ma'ruf nahi munkar, atau menaikkan dirinya pada tingkat moralitas yang tinggi (seperti berperilaku adil, sabar, taat terhadap doktrin Islam dan lain sebagainya). Secara kontinu ia mengembangkan nilai, kepercayaan, dan perilaku-perilaku yang dimunculkan dari pemahaman terhadap al-Qur'an, al-Hadist, ijma' 'ulama, dan fenomena kelembagaan. Hal inilah menurut Schein dikatakan bahwa pendiri organisasi -kiai- merupakan pembentuk dan pembangun budaya organisasi. ${ }^{24}$ Apalagi proses kepemimpinan kedua kiai memiliki proses dua arah, di mana pemimpin mentransformasi pengikutnya dan memungkinkan pengikut untuk menjadi pemimpin yang berlandaskan nilai-nilai kebajikan.

Adanya potensi kebersamaan yang melahirkan konsensus terhadap visi organisasi mendorong penerapan gaya kepemimpinan tersebut. Karenanya, pemimpin bukan satu-satunya yang bertugas memberikan visi gerakan organisasi dan mendiseminasikan kepada pengikutnya. Ia justru menjadi penerjemah visi bersama pengikutnya untuk ditransformasikan dalam bentuk kerja nyata kolektif mutual. Di organisasi sendiri terjadi proses dialektis mencapai mufakat antara pemimpin dan pengikut melalui musyawarah dengan mengikat diri mereka pada nilai normatif al-Qur'an dan al-Hadist. Ini merupakan pengejawantahan satu nilai normatif dalam QS. Al-Syuura ayat 38 .

Ketika ditarik pada konteks pesantren, maka yang perlu dimusyawarahkan adalah persoalan pesantren. Di dalam konsepsi kepemimpinan transformasional kiai, musyawarah merupakan bagian integral dari persoalan amar ma'ruf nahi munkar, serta nasihat tentang kebenaran dan saran yang berlaku sabar kepada yang lain; mencakup pemimpin kepada pengikutnya atau sebaliknya. ${ }^{25} \mathrm{Hal}$ ini merupakan karakteristik dari masyarakat -baca pesantren- yang dibangun berdasarkan nilai Tauhid; yaitu masyarakat yang memungkinkan adanya saling tukar pikiran dan menyampaikan pesan tentang kebenaran dan kebaikan serta terbuka, menurut Madjid. ${ }^{26}$

${ }^{24}$ Edgar H. Schein, Organizational Culture and Leadership. (San Francisco: Jossey-Bass, 2010), 231.

${ }^{25}$ Sanerya Hendrawan, Spiritual Management: From Personal Enlightenment Towards God Corporate Governance (Bandung: Mizan, 2009), 181.

${ }^{26}$ Nurcholish Madjid, Islam Agama Peradaban: Membangun Makna dan Relevansi Doktrin Islam dalam Sejarah (Jakarta: Paramadina, 2000), 14. 
Puncaknya, dalam konteks tersebut, antara diri pemimpin dengan pengikut secara kolektif meningkatkan potensi kemanusiaannya menuju kesempurnaan diri pada dimensi profan maupun transendental. Konsekuensinya, mereka mempunyai kemampuan untuk bisa menyatukan misi keduniawian dan kelangitan. Stadium ini dalam terminologi kepemimpinan profetik dikatakan sebagai manusia setingkat dewa dan manusia setengah malaikat; yang merupakan puncak nilai-nilai adiluhung. ${ }^{27}$ Ada konteks ini pula, kiai bisa mengembangkan pesantren melalui pola ketauladanan; sebagaimana dalam salah satu riset dikatakan bahwa diri kiai merupakan sosok yang menjunjung tinggi nilai-nilai luhur sehingga ia bisa ditempatkan sebagai referensi untuk bertindak dan mengembangkan lembaga pesantren. ${ }^{28}$

\section{Implikasi Kepemimpinan Transformasional Kiai dalam Pengembangan PFK dan PNIA}

Kepemimpinan kiai PFK dan PNIA ternyata bisa membangun nilai dan norma kelembagaan pesantren yang bersumber dari ajaranajaran normatif Islam (al-Qur'an dan al-Hadits). Bahkan dalam salah satu riset, kiai PNIA sangat efektif dalam mengembangkan budaya organisasi pesantren. ${ }^{29}$ Wajar apabila sivitas pesantren sendiri menerima bangunan nilai dan norma tersebut tanpa ada paksaan dan mereka berharap mendapatkan barakah atau keridhaan illahiah. Pemimpin dan pengikut saling "diuntungkan", keduanya berinteraksi dalam bingkai simbiosis-mutualisme hingga mampu membangun relasi egaliter.

Dari relasi itulah muncul budaya organisasi sebagai penompang untuk mengembangkan pesantren yang di dalamnya terdapat core belief, core values, visi dan misi yang bisa menjadi paradigma dan sekaligus kekuatan penggerak untuk melakukan

${ }^{27}$ Jannus T.H. Siahaan, Memungut Remah-Remah Kehidupan (Jakarta: Yayasan Pustaka Obor Indonesia, 2014), 169.

${ }^{28}$ Ahmad Muflih dkk., "Leadership Evolution of Salafiyah Boarding School Leader at Lirboyo Kediri," International Journal of Business and Management Invention 2, no. 3 (Maret 2014): 34-50.

${ }^{29}$ Abd Muhith, "Transformational Leadership in Establishing Organizational Culture at Gender Pesantren," Global Journal of Arts, Humanities and Social Sciences 6, no. 1 (Januari 2017): 20-35. 
perubahan. ${ }^{30}$ Artinya, core belief dan core values tidak bisa lepas dari kepemimpinan transformasional kiai yang setiap perilakunya terus menerus dibingkai oleh nilai-nilai spiritual. Seluruh perilaku, ucapan dan atribut yang melekat pada pemimpin dimaknai dan menginspirasi pengikutnya, sehingga mereka mempunyai referensi untuk mencontoh. Bisa dikatakan, pemimpin transformasional kiai menjelma menjadi sosok panutan selayaknya nabi Muhammad.

Pemimpin yang demikian dihadapan pengikutnya merupakan pahlawan organisasi atau ketauladanan. Nilai-nilai keagungan yang bersumber dari ajaran keagamaan dan melekat pada diri pemimpin menjadi nilai filosofis-ideologis organisasi hingga ia menginternal pada diri pengikut. Hal inilah yang dikatakan oleh Armstrong ${ }^{31}$ atau Schein $^{32}$ sebagai varian nilai -seperti kesadaran, hasrat afektif, atau keinginan-yang melekat kuat dalam budaya organisasi. Menggunakan pandangan Kotter \& Hassket yang membagi budaya organisasi pada dua tingkatan yaitu tampak dan tidak tampak, ${ }^{33}$ maka nilai tersebut merupakan nilai yang tidak tampak dan sangat sulit berubah, dan jika mengalami perubahan butuh waktu relatif lama.

Di satu sisi, kepemimpinan transformasional kiai juga berdampak pada pengembangan sumberdaya manusia. Yukl menyatakan bahwa pemimpin transformasional dianggap sebagai pemimpin yang menumbuhkan pemimpin yang lain dengan meningkatkan kesadaran dan meningkatkan cita-cita serta nilainilai moral untuk terus dikembangkan potensi kemanusiaannya. ${ }^{34}$ Tidak heran, perilaku kepemimpinan transformasional kedua kiai dengan berpegang teguh pada nilai-nilai normatif spiritualitas bisa menciptakan perubahan dan memberdayakan civitas pesantren secara totalitas mulai dari aspek kecerdasan intelektual, emosional, dan spiritual; dari dimensi kebutuhan jasmaniah sampai rohaniah.

30 Tobroni, Pendidikan Islam: dari Dimensi Paradigma Teologis, Filosofis dan Spiritualitas Hingga Dimensi Praktis Normatif (Jakarta: Mitra Wacana Media, 2015), 115.

${ }^{31}$ Michael Armstrong, Armstrong's Handbook of Management and Leadership: a Guide to Managing for Results, 141-43.

${ }^{32}$ Edgar H. Schein, Organizational Culture and Leadership.

${ }^{33}$ John P. Kotter dan James L. Heskett, Corporate Culture and Performance (New York: The Free Press, 1992), 5.

${ }^{34}$ Gary Yukl, Leadership in Organizations, 338-39. 
Karenanya, pengikut kepemimpinan transformasional mulai membentuk karakter diri mereka dengan sifat profesionalisme dan peningkatan keterampilan. Mereka cenderung memaknai pengabdian dan orientasi hidupnya, sehingga mereka rela mengorbankan seluruh potensinya untuk kepentingan organisasi. Hal ini bisa menjadi standar untuk mengukur tinggi rendahnya komitmen pengikut -atau mungkin pemimpin. Kenyataannya bentuk komitmen yang muncul di PFK dan PNIA tidak hanya untuk kepentingan organisasi, tetapi juga untuk kepentingan umat yang diorientasikan pada pengabdian dirinya kepada Tuhan. Mereka telah melampui egosentris diri menuju pada sikap altruistik spiritual yang di dalamnya terdapat kesadaran ketuhanan. Dalam konsep Islam, keadaan mereka dapat dikatakan pribadi sempurna yang menerapkan ihsan (muhsin).

Dengan demikian, perilaku kepemimpinan kiai tersebut merupakan bagian sosok muhsin yang memiliki penghayatan pekat kehadiran Tuhan di kehidupan organisasi dan dijemahkan dalam bentuk tindakan altruistik. Fungsi kepemimpinannya difokuskan pada pembentukan tata keorganisasian profesional dengan meningkatkan pemberdayaan potensi pengikut dan sikap mencerahkan imam dan hati nuraninya. Ia memunculkan perilaku kepemimpinannya melalui kesadaran dirinya sebagai insan spiritual yaitu insan yang memiliki kesadaran ketuhanan untuk menebar kebaikan melalui amal shaleh. Sesorang yang sudah mencapai derajat ini bisa dikatakan telah mencapai kebesaran spiritual individual (individual spiritual greatness).

Oleh sebab itu, kesadaran ketuhanan yang diterjemahkan dalam bentuk sikap altruistik (amal shaleh) sebagai sikap ihsan. Ketika diterapkan dalam organisasi memiliki implikasi yang nyata terhadap tatanan keorganisasian maupun terhadap karakter sumberdaya manusia. Ihsan sendiri merupakan wujud internalisasi dari prinsip Islam dan keimanan seseorang agar mampu mencapai kondisi yang ideal dalam menjalani kehidupannya. Seseorang yang mencapai titik ihsan, ia berada pada tingkat kehidupan yang menyenangkan penuh dengan kerelaan (fi isyat radhiyah). Ihsan memungkinkan masyarakat 
-baca komunitas pesantren- untuk berada dalam cinta, kasih sayang, persaudaraan, dan persahabatan.. ${ }^{35}$ Artinya, kebesaran spiritual individual merupakan bentuk aktualisasi dari perwujudan ihsan di dalam perilaku keseharian mereka.

Berdasarkan deskripsi tersebut, bisa diformulasikan teori kepemimpinan transformasional profetik; suatu teori yang memberikan pembeda dengan teori kepemimpinan transformasional Bass. Pada konteks ini ada upaya rekonstruksi terhadap teori "Four I's" (4-I) menjadi "Five I's" (5-I) dengan memasukkan "individual spiritual greatness" sebagai dimensi integratif dalam perilaku pemimpin transformasional profetik, yaitu idealized influence, inspirational motivasional, intellectual stimulation, individual consideration, dan individual spiritual greatness.

Substansi kepemimpinan transformasional profetik untuk melakukan proses transformasi sistem ke arah yang lebih baik dengan berperan meningkatkan potensi sumberdaya manusia (liberasi) melalui perilaku altruistik (humanisasi) untuk mencapai tujuan duniawi dan ukhrawi berlandaskan kesadaran ketuhanan (transendensi). Proses transformasi yang diwujudkan tidak hanya bersifat rasional (dimensi duniawi), tetapi diorientasikan membangun kelembagaan profesional melalui sumberdaya manusia yang memiliki kesadaran ketuhanan (dimensi akhirat (transendental)) untuk mencapai kesempurnaan dunia dan akhirat. Esensi transformasional profetik ini selaras dengan spirit nabi Muhammad ketika Hijrah dari dari Mekkah ke Yastrib (Madinah).

Kiai yang menerapkan gaya kepemimpinan transformasional profetik di pesantren merupakan sosok kiai bidimensional. Semua diarahkan pada dua aspek yaitu jiwa dan raga, diorientasikan pada dua dimensi yaitu keduniawian dan keakhiratan, dan lembaga pesantren dibangun dengan landasan ibadah. Gaya kepemimpinan ini membawa dimensi keduniawian ke dimensi spiritual (keilahian); atau bisa dikatakan gaya kepemimpinan yang mengintegrasikan domain profan dengan transendental.

${ }^{35}$ Imam Taufiq, Al-Qur'an Bukan Kitab Teror: Membangun Perdamaian Berbasis a-Qur'an (Yogyakarta: Bentang, 2016), 78. 
Menariknya, gaya kepemimpinan ini tidak bergantung pada pemaknaan simbol-simbol yang muncul dan dipakai pemimpinpengikut sebagaimana yang dikatakan interaksionisme simbolik. Di pesantren relasi antara kiai dengan civitas pesantren menciptakan perilaku kepemimpinan transformasional profetik tidak hanya berdasarkan pada makna dan simbol yang bersifat horizontal (antar manusia dengan manusia). Namun, tindakan mereka muncul berdasarkan kesadaran diri sebagai makhluk berketuhanan (spiritual). Artinya, mereka bertindak berdasarkan kesadaran ketuhanan -lazim disebut sikap ihsan (muhsin). Bahwasannya Allah senantiasa bersama dengan dirinya hingga Allah bukan hanya Maha Hadir (Omni Present), tetapi juga Maha Dekat (In-Manent). Melalui kesadaran ini, mereka terus menampilkan tindakan-tindakan yang memiliki relevansi dengan nilai-nilai spiritual. Artinya, tindakan mereka tidak hanya merespon stimulus yang muncul melalui proses pemahaman dan penafsiran simbol, tetapi ada pertimbangan lain untuk bertindak yaitu nilai spiritual (ketuhanan). Ini sebuah proses konstruksi tindakan sosial kehidupan manusia yang terus bergerak secara dinamis menuju kesempurnaan diri sebagai makhluk sosial dan berketuhanan.

\section{E. Simpulan}

Pesantren dengan sifat akomodatif-selektif berbasis pada nilainilai kepesantrenan dimotori oleh kiai yang mempunyai pandangan progresif bergerak memajukan sistem pendidikan kelembagaannya sendiri. Dengan berpijak pada visi misi pesantren, AMA dan MA mengembangkan pesantren melalui integrasi antara tradisi lama dengan tradisi baru; antara dimensi rasionalitas dengan spiritualitas yang diorientasikan untuk mencapai tujuan pesantren yang bersifat profan dan transendental. Bahkan melalui gaya kepemimpinan transformasional mereka mengedepankan sikap altruistik spiritual untuk mengembangkan, meningkatkan dan memperdayakan potensi civitas pesantren mencapai tujuan keduniawian dan keakhiratan. Perilaku mereka yang melekat kuat, antara lain: sikap humanistikaltruistik (humanisasi), sikap membangun perilaku konstruktif (mencegah yang destruktif) (liberasi), dan sikap meningkatkan ketaqwaan dan keimanan kepada Allah (transendensi)[.] 


\section{REFERENSI}

Abd Muhith. "Transformational Leadership in Establishing Organizational Culture at Gender Pesantren." Global Journal of Arts, Humanities and Social Sciences 6, no. 1 (Januari 2017).

Abdurrahman Wahid. Menggerakkan Tradisi. Yogyakarta: LKiS, 2010.

Ahmad Muflih, Armanu, Djumahir, dan Solimun. "Leadership Evolution of Salafiyah Boarding School Leader at Lirboyo Kediri." International Journal of Business and Management Invention 2, no. 3 (Maret 2014).

Ali Anwar. Pembaruan Pendidikan di Pesantren Lirboyo Kediri. Yogyakarta: Pustaka Pelajar, 2011.

Amir Fadhilah. "Struktur Dan Pola Kepemimpinan Kyai Dalam Pesantren Di Jawa." HUNAFA: Jurnal Studia Islamika 8, no. 1 (15 Juni 2011): 101-20. https://doi.org/10.24239/jsi. v8i1.89.101- 120.

Azyumardi Azra. Pendidikan Islam: Tradisi dan Modernisasi Menuju Milenium Baru. Jakarta: Kalimah, 2001.

Bernard M. Bass, dan Ronald E. Riggio. Transformational Leadership. New Jersey: Lawrence Erlbaum Associates, Inc, 2006.

Budhy Munawar Rachman. Kontekstualisasi Doktrin Islam dalam Sejarah. Jakarta: Paramadina, 1995.

Djohan Effendi. Pesan-Pesan al-Qur'an: Mencoba Mengerti Intisari Kitab Suci. Jakarta: Serambi, 2012.

Edgar H. Schein. Organizational Culture and Leadership. San Francisco: Jossey-Bass, 2010.

Fred Luthans. Organizational Behavior: An Evidance-Based Approach. New York: McGraw-Hill, 2011.

Gary Yukl. Leadership in Organizations. New Jersey: Prentice Hall, 2010.

Hiroko Horikoshi. Kyai dan Perubahan Sosial. Peterj.: Umar Basalim $\mathcal{E}$ Andi Muarly Sunrawa. Jakarta: P3M, 1987.

Imam Mustofa. "Menjadikan Pesantren Sebagai Pusat Peradaban Muslim di Indonesia." Millah: Jurnal Studi Agama 11, no. 
1 (2011): 75-108. https://doi.org/10.20885/millah.vol11. iss1. art4.

Imam Taufiq. Al-Qur'an Bukan Kitab Teror: Membangun Perdamaian Berbasis a-Qur'an. Yogyakarta: Bentang, 2016.

Ira M. Lapidus. Sejarah Sosial Ummat Islam: Bagian Kesatu \& Dua Peterj.: Ghufron A. Mas'adi. Jakarta: Rajawali Pers, 2000.

Jannus T.H. Siahaan. Memungut Remah-Remah Kehidupan. Jakarta: Yayasan Pustaka Obor Indonesia, 2014.

John P. Kotter, dan James L. Heskett. Corporate Culture and Performance. New York: The Free Press, 1992.

Laban P. Ayiro. "Transformational Leadership and School Outcomes in Kenya: Does Emotional Intelligence Matter?" FIRE: Forum for International Research in Education 1, no. 1 (2014): 4.

Michael Armstrong. Armstrong's Handbook of Management and Leadership: a Guide to Managing for Results. London: Kogan Page, 2009.

Ngainun Na'im. "Pesantren dan Pembentukan Manusia Karakter." Al-Afkar: Journal for Islamic Studies 1, no. 2 (Maret 2013).

Noor Hamid, dan Muhammad Iqbal Juliansyahzen. "Prophetic Leadership in Pesantren Education: Study at Pondok Pesantren Universitas Islam Indonesia." Jurnal Pendidikan Islam 6, no. 2 (27 Desember 2017): 349. https://doi.org/10.14421/ jpi.2017.62.349-369.

Nur Khusniyah Indrawati. "Management by Inspiration: Implementation of Transformational Leadership on Business at Pondok Pesantren*) Sunan Drajat." Procedia - Social and Behavioral Sciences 115, no. 21 (21 Februari 2014): 79-90. https:/ / doi.org/10.1016/j.sbspro.2014.02.417.

Nurcholish Madjid. Islam Agama Peradaban: Membangun Makna dan Relevansi Doktrin Islam dalam Sejarah. Jakarta: Paramadina, 2000.

Prabowo Adi Widayat. "Kepemimpinan Profetik: Rekonstruksi Model Kepemimpinan Berkarakter Keindonesiaan." AKADEMIKA: Jurnal Pemikiran Islam 19, no. 1 (19 Maret 2014): 18-34. 
Sanerya Hendrawan. Spiritual Management: From Personal Enlightenment Towards God Corporate Governance. Bandung: Mizan, 2009.

Septalina Pradini, Hadi S Alikodra, Hasim, dan Tri Pranadji. "Pesantren Transformation System in The Food Sustainability." International Journal of Development and Economic Sustainability 4, no. 2 (April 2016).

Stephen P. Robbins, dan Mary Coulter. Management. New Jersey: Prentice Hall, 2012.

Syamsul Ma'arif. "Pola Hubungan Patron-Client Kiai dan Santri di Pesantren." Ta'dib: Journal of Islamic Education (Jurnal Pendidikan Islam) 15, no. 02 (2010): 273-96.

Taufiq Ismail, dkk. Membangun Kemandirian Umat di Pedesaan: Ikhtiar dan Peran Pesantren Pertanian Darul Fallah 1960-2000. Bogor: Pesantren Pertanian Darul Fallah, 2000.

Tobroni. Pendidikan Islam: dari Dimensi Paradigma Teologis, Filosofis dan Spiritualitas Hingga Dimensi Praktis Normatif. Jakarta: Mitra Wacana Media, 2015.

Ulf Spears. Coaching Leadership Families: Using the Leadership Family Model to Coach, Mentor and Multiply Healthy Families. Oregon: Xlibris Corporation, 2012.

Zamakhsyari Dhofier. Tradisi Pesantren: Studi Tentang Pandangan Hidup Kiai. Jakarta: LP3ES, 1994. 
